\title{
MODEL PENDEKATAN ALAT UJI KEPADATAN RINGAN UNTUK TANAH DI LABORATORIUM (PENELITIAN LANJUTAN I)
}

\author{
(Model Approach Of Tool Test Light Density For Land In Laboratory (Advanced Research I)
}

\author{
ANWAR MUDA \\ Satuan Kerja Pelaksanaan Jalan Nasional Wilayah II Sumatera Utara \\ Balai Besar Pelaksanaan Jalan Nasional II Medan \\ Email : anwarmuda@gmail.com
}

\begin{abstract}
The study, entitled "the application of the Model as a means of Testing the density of light to the ground in the lab (Advanced Studies 1)". Backed by research from previous research, entitled "the application of the Model as a means of Testing the density of light for the soil in the laboratory", in previous studies of soil clays used example is the land of clays from the village of Baringan, the city of Palangkaraya. While soil samples in this study used is the land of the village of Palopat Sub-district of Padang Sidempuan PK, Southeast, or rather in the STA 500 Padang Sidempuan 4 heading Mandailing Natal. This study aimed to compare the CBR and UCS clay stabilized sand and cement for the pavement

The research aims to conduct an analysis of the maximum density of soil clays based on Models by as much as 33 collisions per layer as much as 2 layers obtained the maximum dry weight ( $y d$ max) and optimum moisture content ( $w$ opt) and SNI 1742:2008. If the level of the margin of error is obtained and has $5 \%<$ assessment of performance against the same heap, then the Model can be used as a means of testing the density of light to the ground in a lab that has the same standard with SNI 1742:2008.

The results showed, that the maximum density of soil clays based on the Model there is a confidence level $98.04 \% \geq 95 \%$ and a margin of error of $196 \% \leq 5 \%$ against the weight of the dry content maximum (max yd) and $98.72 \% \geq 95 \%$ and a margin of error of $1.28 \% \leq 5 \%$ towards the optimum water content (opt.). From this analysis, based on the Model of the compaction time 33 collisions per layer as much as 2 layers have a confidence level $\geq 95 \%$ against SNI 1742:2008 and have the same assessment on performance of the heap, so Models qualifies as a light density test tools for soil in the laboratory that has the same standard with SNI 1742:2008.
\end{abstract}

Keywords: model, approach, test tools, light, soil density

\section{ABSTRAK}

Penelitian ini berjudul "Aplikasi Model Sebagai Alat Uji Kepadatan Ringan Untuk Tanah di Laboratorium (Penelitian Lanjutan 1)". Penelitian dilatarbelakangi dari penelitian sebelumnya yang berjudul "Aplikasi Model Sebagai Alat Uji Kepadatan Ringan Untuk Tanah di Laboratorium", Dalam penelitian sebelumnya contoh tanah lempung yang digunakan adalah tanah lempung dari Desa Baringan, Kota Palangkaraya. Sedangkan dalam penelitian ini contoh tanah yang digunakan adalah tanah Desa Palopat PK, Kecamatan Padang Sidempuan Tenggara, atau tepatnya di STA 4+500 Padang Sidempuan menuju Mandailing Natal.

Penelitian bertujuan untuk melakukan analisis kepadatan maksimum tanah lempung berdasarkan Model sebanyak 33 tumbukan per lapis sebanyak 2 lapis yang diperoleh berat isi kering maksimum (yd maks) dan kadar air optimum (w opt) dan SNI 1742:2008. Jika tingkat margin error didapatkan $<5 \%$ dan memiliki penilaian yang sama terhadap kinerja timbunan, maka Model dapat digunakan sebagai alat uji kepadatan ringan untuk tanah di laboratorium yang memiliki standar yang sama dengan SNI 1742:2008.

Hasil penelitian menunjukkan, bahwa kepadatan maksimum tanah lempung berdasarkan Model terdapat tingkat keyakinan $98.04 \% \geq 95 \%$ dan margin error $196 \% \leq 5 \%$ terhadap berat isi kering maksimum ( $y d$ maks) dan $98.72 \% \geq 95 \%$ dan margin error $1.28 \% \leq 5 \%$ terhadap kadar air optimum (w opt). Dari analisis ini, pemadatan berdasarkan Model saat 33 tumbukan per lapis sebanyak 2 lapis memiliki tingkat keyakinan $\geq 95 \%$ terhadap SNI 1742:2008 dan memiliki penilaian yang sama terhadap kinerja timbunan, sehingga Model memenuhi syarat sebagai alat uji kepadatan ringan untuk tanah di laboratorium yang memiliki standar yang sama dengan SNI 1742:2008. 


\section{PENDAHULUAN}

Pada umumnya tanah yang dipadatkan berdasarkan SNI 1742:2008, adalah tanah lolos saringan no.4 dan dipadatkan dalam mould dengan diameter cetakan 101,60 mm dan tinggi cetakan 116,43 mm serta volume cetakan 943 $\mathrm{cm}^{3}$ dengan alat penumbuk $2,50 \mathrm{~kg}$ dan tinggi jatuh $30.50 \mathrm{~cm}$. Kemudian, tanah tersebut dipadatkan dalam tiga lapis dimana setiap lapis sebanyak 25 tumbukan. Pemadatan ini diulang paling sedikit 5 kali dengan kadar air tiap percobaan divariasikan kemudian digambarkan sebuah grafik hubungan kadar air dan berat volume keringnya. Grafik ini akan memperlihatkan nilai kadar air terbaik untuk mencapai berat volume kering terbesar atau kepadatan maksimum.

Sedangkan tanah yang dipadatkan berdasarkan Model juga sama dengan SNI 1742:2008 yaitu tanah yang lolos saringan no. 4. Namun Model dipadatkan dalam mould diameter cetakan $70 \mathrm{~mm}$ dan tinggi cetakan $75 \mathrm{~mm}$ serta volume cetakan $288.50 \mathrm{~cm}^{3}$ dengan penumbuk 2 $\mathrm{kg}$ dan tinggi jatuh $25 \mathrm{~cm}$. Kemudian, tanah tersebut dipadatkan dalam dua lapis dimana setiap lapis sebanyak 33 tumbukan. Pemadatan ini diulang paling sedikit 5 kali dengan kadar air tiap percobaan divariasikan kemudian digambarkan sebuah grafik hubungan kadar air dan berat volume keringnya. Grafik ini akan memperlihatkan nilai kadar air terbaik untuk mencapai berat volume kering terbesar atau kepadatan maksimum.

Pada penelitian sebelumnya telah dilakukan pemadatan tanah berdasarkan Model dengan judul "Aplikasi Model Sebagai Alat Uji Kepadatan Ringan Untuk Tanah di Laboratorium".
Dari penelitian tersebut, bahwa contoh tanah yang akan digunakan adalah tanah lempung Desa Baringin, Kota Palangkaraya. Kemudian, tanah ini termasuk jenis lanau-lempung dengan perkiraan kinerja timbunan buruk sampai bagus atau jenis lempung dengan perkiraan kinerja timbunan buruk sampai sedang, Dari analisis ini, terlihat bahwa pemadatan Model pada saat 33 tumbukan per lapis sebanyak 2 lapis dapat meningkatkan tingkat keyakinan seiring menurunnya margin error terhadap SNI 1742:2008 dan memiliki penilaian yang sama terhadap kinerja timbunan, sehingga tingkat keyakinan penggunaan Model sebagai alat uji kepadatan ringan untuk tanah di laboratorium semakin bertambah seiring menurunnya margin error

Hasil penelitian sebelumnya yang berjudul "Aplikasi Model Sebagai Alat Uji Kepadatan Ringan Untuk Tanah di Laboratorium" didapatkan bahwa kepadatan maksimum tanah lempung berdasarkan SNI 1742:2008 didapatkan berat isi kering maksimum ( $\mathrm{yd}$ maks) $1.51 \mathrm{gr} / \mathrm{cm}^{3}$ dan kadar air optimum (w opt) $22.78 \%$. Tanah ini termasuk jenis lanau-lempung dengan perkiraan kinerja timbunan buruk sampai bagus atau lempung dengan perkiraan kinerja timbunan buruk sampai sedang.

Kemudian, kepadatan maksimum tanah lempung berdasarkan Model saat 33 tumbukan per lapis sebanyak 2 lapis didapatkan bahwa berat isi kering maksimum ( $\gamma d$ maks) $1.51 \mathrm{gr} / \mathrm{cm}^{3}$ dan kadar air optimum (w opt) $23.61 \%$. Tanah ini termasuk jenis lanau-lempung dengan perkiraan kinerja timbunan buruk sampai bagus atau lempung dengan perkiraan kinerja timbunan buruk sampai sedang. 
Dari analisis ini, kepadatan maksimum tanah lempung berdasarkan Model terdapat tingkat keyakinan $100.00 \% \geq 95 \%$ dan margin error $0.00 \% \leq 5 \%$ terhadap berat isi kering maksimum ( $y d$ maks) dan $96.48 \% \geq 95 \%$ dan margin error $3.52 \% \leq 5 \%$ terhadap kadar air optimum (w opt). Dari analisis ini, pemadatan berdasarkan Model saat 33 tumbukan per lapis sebanyak 2 lapis memiliki tingkat keyakinan $\geq$ 95\% terhadap SNI 1742:2008 dan memiliki penilaian yang sama terhadap kinerja timbunan, sehingga aplikasi Model memenuhi syarat sebagai alat uji kepadatan ringan untuk tanah di laboratorium yang memiliki standar yang sama dengan SNI 1742:2008

Pada penelitian ini yang berjudul "Aplikasi Model Sebagai Alat Uji Kepadatan Ringan Untuk Tanah di Laboratorium (Penelitian Lanjutan I" akan dilakukan dengan mengambil contoh tanah dari Desa Sihitang, Kecamatan Padang Sidempuan Tenggara, Kota Padang Sidempuan atau tepatnya di STA 4+500 Padang Sidempuan menuju Mandailing Natal. Contoh tanah yang akan diuji antara lain ukuran butir tanah, berat jenis dan batas plastis. Kemudian dilanjutkan dengan pengujian pemadatan berdasarkan Model sebanyak 33 tumbukan per lapis sebanyak 2 lapis dan sama halnya dengan pemadatan berdasarkan SNI 1742-2008. Selanjutnya, setelah didapatkan hasil pemadatan dari kedua metode tersebut akan dilakukan penilaian terhadap kinerja timbunan dan menganalisis tingkat margin error terhadap berat isi kering maksimum ( $y d$ maks) dan kadar air optimum (w opt). Jika tingkat margin error didapatkan $<5 \%$ dan memiliki penilaian yang sama terhadap kinerja timbunan, maka Model dapat digunakan sebagai alat uji kepadatan ringan untuk tanah di laboratorium yang memiliki standar yang sama dengan SNI 1742:2008.

\section{KAJIAN PUSTAKA}

\section{Ratna Yuniarti (2008)}

Ratna Yuniarti (2008) melakukan penelitian yang berjudul Perbandingan Nilai Daya Dukung Tanah Dasar Badan Jalan Yang Distabilisasi Semen dan Abu Sekam Padi menyatakan bahwa tanah Awu Kecamatan Penujak Kabupaten Lombok Tengah termasuk termasuk tanah jenis lempung ekspansif dengan Indeks Plastisitas (PI) sebesar $84,10 \%$. Jika tanah memiliki PI > 17\%, umumnya tanah ini termasuk jenis lempung bersifat kohesif dan plastisitas tinggi. Kemudian dari hasil uji pemadatan standar Proctor didapatkan nilai berat volume kering maksimum (yd maks) sebesar 1,165 gr/ $\mathrm{cm}^{3}$ dan kadar air optimum (w opt) sebesar 37,5\%.

\section{Warsiti (2009)}

Warsiti, (2009), melakukan penelitian yang berjudul Meningkatkan Nilai CBR dan Memperkecil Swelling Tanah Sub Grade Dengan Metode Stabilisasi Tanah dan Kapur yang dipublikasikan dalam Jurnal Wahana TEKNIK SIPIL Vol. 14 No. 1, April 2009 Jurusan Teknik Sipil Politeknik Negeri Semarang. Dalam penelitiannya mengangkat permasalahan kualitas tanah asli dengan jenis lempung berlanau. Berdasarkan hasil penelitian, bahwa pengujian mekanis dengan metode standar tanah asli mempunyai kepadatan kering maksimum ( $\mathrm{yd}$ maks) $1,485 \mathrm{gr} / \mathrm{cm}^{3}$ dan kadar air optimum (w opt) $24 \%$

\section{Deny Setyadi (2010)}

Deni Setyadi (2010) dalam skripsinya yang berjudul Pengaruh Penambahan Tanah Gadong 
Pada Stabilisasi Tanah Lempung Tanon Dengan Semen (Studi Kasus Kerusakan Jalan Desa Jono, Tanon, Sragen) menyatakan bahwa tanah gadong merupakan tanah lempung berlanau, terklasifikasi tanah berbutir halus (fine grained) dengan simbol ML (untuk sistem USCS) dan A-5 (untuk system $A A S H T O$ ), dengan distribusi butiran sebagai berikut: kerikil $($ gravel $)=0 \%$, pasir $($ sand $)=10 \%$, lanau $($ silt $)=88 \%$ dan lempung $($ clay $)=2 \%$, mempunyai berat jenis tanah (Gs) $=2.223$. Kemudian dari hasil pengujian standar Proctor bahwa tanah ini mempunyai kepadatan kering maksimum ( $y d$ maks) $1,09 \mathrm{gr} / \mathrm{cm}^{3}$ serta kadar air optimum (w opt) sebesar 37\%.

\section{Anwar Muda (2016)}

Anwar Muda (2016), melakukan penelitian dengan judul Model Pendekatan Alat Uji Kepadatan Ringan Untuk Tanah di Laboratorium yang dipublikasikan Infoteknik, Volume 17, Nomor 1, Juni 2016, Fakultas Teknik, Universitas Lambung Mangkurat, Banjarmasin. Latar belakang penelitian tersebut bahwa selama ini pengujian pemadatan ringan untuk tanah di laboratorium dengan peralatan standar SNI 1742:2008. Namun peralatan ini belum pernah dilakukan sebagai pembanding atau model pendekatan yang memiliki standar yang sama dengan SNI 1742:2008 dengan margin error $\leq$ $5 \%$.

Penelitian bertujuan untuk menentukan apakah alat uji kepadatan ringan untuk tanah di laboratorium dengan model dapat digunakan sebagai alat uji kepadatan ringan untuk tanah di laboratorium yang memiliki standar yang sama dengan SNI 1742:2008 dengan margin error s $5 \%$ dan memberikan penilaian yang sama terhadap kinerja timbunan
Hasil penelitian menunjukkan, kepadatan maksimum tanah lempung Palangka Raya berdasarkan peralatan standar SNI 1742:2008 diperoleh berat isi kering maksimum ( $y d$ maks) $1.51 \mathrm{gr} / \mathrm{cm}^{3}$ dan kadar air optimum (w opt) 25.74 $\%$ dan tanah ini termasuk lanau-lempung dengan perkiraan kinerja timbunan buruk sampai bagus atau lempung dengan perkiraan kinerja timbunan buruk sampai sedang.

Sedangkan kepadatan maksimum tanah lempung berdasarkan Model untuk 5, 10, dan 15 tumbukan per lapis sebanyak 2 lapis mempunyai berat isi kering maksimum ( $y d$ maks) dan kadar air optimum (w opt) dengan margin error $>5 \%$ terhadap SNI 1742:2008 dan tidak memiliki penilaian yang sama dengan SNI 1742:2008 terhadap kinerja timbunan, sehingga model belum memenuhi syarat sebagai alat uji kepadatan ringan untuk tanah di laboratorium.

Sedangkan untuk 20 dan 25 tumbukan per lapis sebanyak 2 lapis, diperoleh berat isi kering maksimum ( $y d$ maks) dan kadar air optimum (w opt) dengan margin error $<5 \%$ terhadap SNI 1742:2008, namun belum memiliki penilaian yang sama dengan SNI 1742:2008 terhadap kinerja timbunan, sehingga model belum memenuhi syarat sebagai alat uji kepadatan ringan untuk tanah di laboratorium.

Untuk 30 tumbukan per lapis sebanyak 2 lapis, mempunyai berat isi kering maksimum ( $\mathrm{yd}$ maks) dan kadar air optimum (w opt) dengan margin error $<5 \%$ terhadap SNI 1742:2008 dan memiliki penilaian yang sama dengan SNI 1742:2008 terhadap kinerja timbunan, maka model memenuhi syarat sebagai alat uji kepadatan ringan untuk tanah di laboratorium dan 
memiliki standar yang sama dengan SNI1742:2008

\section{Anwar Muda (2016)}

Anwar Muda (2016), melakukan penelitian dengan judul Aplikasi Model Sebagai Alat Uji Kepadatan Ringan Untuk Tanah di Laboratorium. Latar belakang penelitian tersebut bahwa selama ini pengujian pemadatan ringan untuk tanah di laboratorium dengan peralatan standar $\mathrm{SNI}$ 1742:2008. Namun peralatan ini belum pernah dilakukan sebagai pembanding atau model pendekatan yang memiliki standar yang sama dengan SNI 1742:2008 dengan margin error $\leq$ $5 \%$.

Penelitian bertujuan untuk menentukan apakah alat uji kepadatan ringan untuk tanah di laboratorium dengan model dapat digunakan sebagai alat uji kepadatan ringan untuk tanah di laboratorium yang memiliki standar yang sama dengan SNI 1742:2008 dengan margin error s $5 \%$ dan memberikan penilaian yang sama terhadap kinerja timbunan

Hasil penelitian menunjukkan, kepadatan maksimum tanah lempung Palangka Raya berdasarkan peralatan standar SNI 1742:2008 diperoleh berat isi kering maksimum ( $\gamma d$ maks) $1.51 \mathrm{gr} / \mathrm{cm}^{3}$ dan kadar air optimum (w opt) 25.74 $\%$ dan tanah ini termasuk lanau-lempung dengan perkiraan kinerja timbunan buruk sampai bagus atau lempung dengan perkiraan kinerja timbunan buruk sampai sedang.

Sedangkan kepadatan maksimum tanah lempung berdasarkan Model untuk 5, 10, dan 15 tumbukan per lapis sebanyak 2 lapis mempunyai berat isi kering maksimum ( $\mathrm{yd}$ maks) dan kadar air optimum (w opt) dengan margin error $>5 \%$ terhadap SNI 1742:2008 dan tidak memiliki penilaian yang sama dengan SNI 1742:2008 terhadap kinerja timbunan, sehingga model belum memenuhi syarat sebagai alat uji kepadatan ringan untuk tanah di laboratorium.

Sedangkan untuk 20 dan 25 tumbukan per lapis sebanyak 2 lapis, diperoleh berat isi kering maksimum ( $y d$ maks) dan kadar air optimum ( $w$ opt) dengan margin error $<5 \%$ terhadap SNI 1742:2008, namun belum memiliki penilaian yang sama dengan SNI 1742:2008 terhadap kinerja timbunan, sehingga model belum memenuhi syarat sebagai alat uji kepadatan ringan untuk tanah di laboratorium.

Untuk 30 tumbukan per lapis sebanyak 2 lapis, mempunyai berat isi kering maksimum ( $\mathrm{yd}$ maks) dan kadar air optimum (w opt) dengan margin error < 5\% terhadap SNI 1742:2008 dan memiliki penilaian yang sama dengan SNI 1742:2008 terhadap kinerja timbunan, maka model memenuhi syarat sebagai alat uji kepadatan ringan untuk tanah di laboratorium dan memiliki standar yang sama dengan SNI1742:2008.

\section{METODE PENELITIAN}

Dalam sebuah penelitian tidak selalu bisa diharapkan betul-betul benar yakin $100 \%$. Karena itu, didalam sebuah penelitian diperlukan seberapa dekat hasil dari sampel dengan hasil kenyataannya (margin error). Margin error adalah tingkat kesalahan sampel atas populasi yang ditentukan oleh peneliti sebelum melakukan penelitian. Pada umumnya asumsi taraf kesalahan hasil penelitian sudah ditentukan batas kesalahan 5\%, Kretjie dan Morgan (www. slideshare.net, diakses 6/8/2014). Pada penelitian ini akan dilakukan asumsi taraf hasil penelitian 
sampai batas 0.05 atau $5 \%$ saja. Maksudnya hanya ada 0,05 atau $5 \%$ saja kesalahan karena kebetulan itu terjadi. Jadi, ini menunjukkan bahwa hasil penelitian yang dilakukan yakin 95\% bahwa hasil penelitian itu benar.

Kemudian, hasil dari penelitian SNI 1742:2008 dan Model memberikan penilaian yang sama terhadap terhadap kinerja timbunan. Maksudnya, hasil penelitian dari SNI 1742:2008 dan Model memberikan penilaian yang sama terhadap kualitas kinerja timbunan.

Adapun proses penelitian ini terlihat seperti pada bagan alir penelitian pada gamar 1 berikut ini :

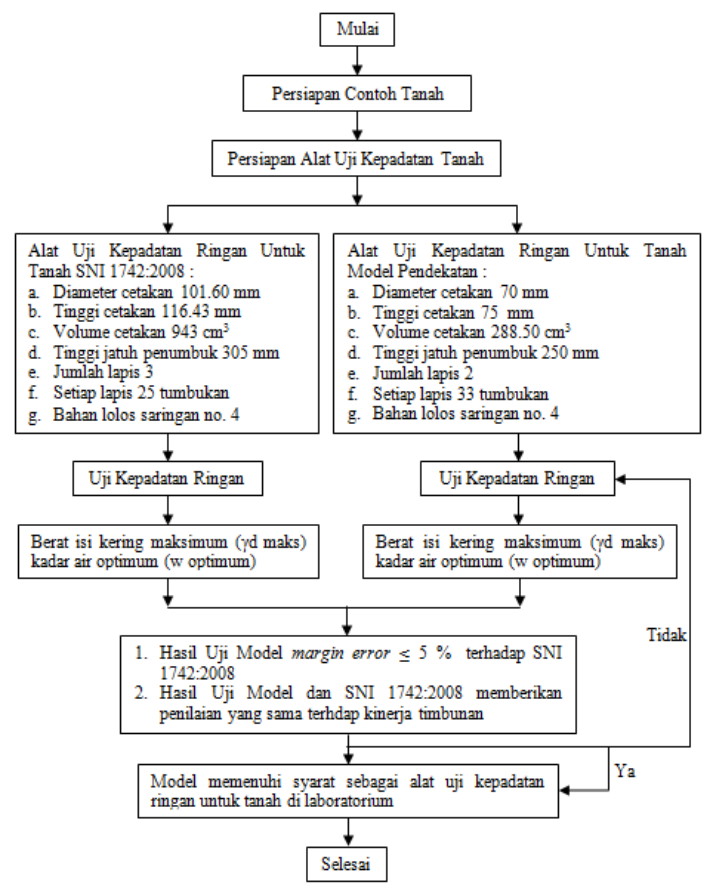

Gambar 1 Diagram Alir Penelitian

\section{HASIL DAN PEMBAHASAN}

\section{Hasil Penelitian}

a. Pengujian Sifat Fisik Tanah
Hasil pengujian sifat fisik tanah Desa Palopat PK, Kecamatan Padang Sidempuan Tenggara dapat dilihat pada Tabel 1 berikut.

Tabel 1 Sifat fisik tanah lempung Palangkaraya

\begin{tabular}{|l|c|c|c|c|}
\hline \multirow{2}{*}{\multicolumn{1}{c|}{ Tipe pengujian }} & \multirow{2}{*}{ Satuan } & \multicolumn{3}{c|}{ Hasil } \\
\cline { 3 - 5 } & & Sampel 1 & Sampel 2 & Rata-rata \\
\hline Lolos saringan No. 200 & $\%$ & 76.32 & 75.96 & 76.14 \\
\hline Batas plastis & $\%$ & 16.30 & 17.58 & 16.94 \\
\hline Berat jenis & & 2.699 & 2.695 & 2.697 \\
\hline
\end{tabular}

Sumber : Hasil analisis (2017)

b. Pengujian Sifat Mekanik Tanah

Hasil pengujian sifat mekanik tanah didasarkan alat uji kepadatan ringan untuk tanah di laboratorium SNI 1742:2008 dan Model Pendekatan seperti pada Tabel 2 pada berikut :

Tabel 2 Pengujian Kepadatan Ringan Untuk Tanah Desa Palopat PK Berdasarkan Alat Uji SNI 1742:2008 dan Model

\begin{tabular}{|c|c|c|c|c|c|c|c|c|c|}
\hline \multicolumn{4}{|c|}{ Kepadatan Tanah } & \multirow{2}{*}{\multicolumn{2}{|c|}{$\begin{array}{l}\text { Tingkat Keyzkinan } \\
\text { (\%) }\end{array}$}} & \multirow{2}{*}{\multicolumn{2}{|c|}{$\begin{array}{l}\text { Margin Error } \\
(\%)\end{array}$}} & \multirow{3}{*}{$\begin{array}{c}\text { Batas } \\
\text { Margin } \\
\text { Emor } \\
\text { (\%) }\end{array}$} & \multirow{3}{*}{ Rekomendasi } \\
\hline sNI1 & 2008 & & & & & & & & \\
\hline 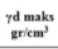 & $\begin{array}{l}\text { Wopt } \\
(\%)\end{array}$ & 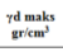 & $\begin{array}{l}\text { Wopt } \\
\%\end{array}$ & 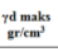 & $\begin{array}{l}\text { Wopt } \\
\%\end{array}$ & 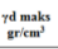 & $\begin{array}{l}\text { Wopt } \\
\%\end{array}$ & & \\
\hline 1.50 & 25.87 & 1.53 & 25.54 & 98.04 & 98.72 & 1.96 & 1.28 & $\leq 5 \%$ & Diterima \\
\hline
\end{tabular}

Sumber : Hasil analisis (2017)

\section{Pembahasan}

a. Sifat Fisik Tanah

Berdasarkan sifat fisik tanah Desa Palopat PK, Kecamatan Padang Sidempuan Tenggara pada Tabel 4.1, bahwa dari uji saringan, tanah ini lolos saringan no. 200 rata-rata sebesar $76.14 \%$. Menurut system klasifikasi Unified (Hardiyatmo, 2012), bahwa tanah ini termasuk sebagai tanah berbutir halus (lanau/lempung), karena tanah ini lolos ayakan saringan no. 200 lebih dari 50\%. Sedangkan klasifikasi AASTHO (Hardiyatmo, 2012), bahwa tanah ini termasuk tanah berbutir halus (lanau/lempung), karena dari hasil 
pengujian, tanah ini lolos saringan no. 200 lebih dari $35 \%$.

Sedangkan dari hasil pengujian berat jenis, bahwa tanah ini memiliki berat jenis (Gs) rata-rata 2.70. Menurut Hardiyatmo (2012), tanah ini mengandung lempung anorganik, karena tanah yang mempunyai berat jenis (Gs) 2,68 - 2,75 termasuk jenis lempung anorganik.

Dari hasil pengujian batas plastis, tanah ini memiliki batas plastis rata-rata rata-rata $16.94 \%$. Menurut system klasifikasi AASTHO (Hardiyatmo, 2012), tanah ini mengandung lempung, karena tanah yang mempunyai batas plastis kurang dari $30 \%$ termasuk dalam kelompok A-7-6 yang memiliki jenis tanah berlempung.

b. Sifat Mekanik Tanah

Berdasarkan hasil pengujian kepadatan ringan berdasarkan SNI 1742:2008 seperti pada Tabel 4.2, bahwa tanah Desa Palopat PK mempunyai berat isi kering maksimum ( $\gamma d$ maks) $1.46 \mathrm{gr} / \mathrm{cm}^{3}$ dan kadar air optimum (w opt) $25.87 \%$. Sehingga, kepadatan tanah maksimum berdasarkan SNI 1742:2008 pada saat kadar air optimum (w opt) 25.87\%.

Menurut Gregg (1960), bahwa tanah Palangkaraya termasuk lanau-lempung dengan perkiraan kinerja timbunan buruk sampai bagus, karena dari hasil pengujian tanah ini mempunyai berat volume kering maksimum ( $y d$ maks) 1.49 $1.88 \mathrm{gr} / \mathrm{cm}^{3}$ dan kadar air optimum (w opt) 10 $30 \%$. Kemudian, tanah ini juga termasuk lempung dengan perkiraan kinerja timbunan buruk sampai sedang, karena dari hasil pengujian tanah ini mempunyai berat volume kering maksimum ( $\gamma d$ maks) $1.41-1.81 \mathrm{gr} / \mathrm{cm}^{3}$ dan kadar air optimum (w opt) $15-30 \%$.
Sedangkan tanah lempung dipadatkan berdasarkan Model saat 33 tumbukan per lapis sebanyak 2 lapis mempunyai berat isi kering maksimum ( $\mathrm{yd}$ maks) $1.53 \mathrm{gr} / \mathrm{cm}^{3}$ dan kadar air optimum (w opt) $25.54 \%$. Hal ini menunjukkan, bahwa kepadatan tanah lempung berdasarkan Model terhadap SNI 1742:2008 terdapat tingkat keyakinan $98.04 \% \geq 95 \%$ dan margin error $1.96 \%$ $\leq 5 \%$. Kemudian, kadar air optimum (w opt) memiliki tingkat keyakinan $98.72 \% \geq 95 \%$ dan margin error $1.28 \% \leq 5 \%$. Sehingga, kepadatan tanah maksimum berdasarkan Model terjadi pada saat kadar air optimum (w opt) 25.54\%. Dari analisis ini diperoleh bahwa aplikasi Model memenuhi syarat sebagai alat uji kepadatan ringan untuk tanah di laboratorium yang memiliki standar yang sama dengan SNI 1742:2008.

Dari hasil pemadatan berdasarkan Model, Gregg (1960), menyatakan, bahwa tanah ini termasuk lanau-lempung dengan perkiraan kinerja timbunan buruk sampai bagus, karena dari hasil pengujian tanah ini mempunyai berat volume kering maksimum ( $y d$ maks) $1.49-1.88 \mathrm{gr} / \mathrm{cm}^{3}$ dan kadar air optimum (w opt) $15-30 \%$. Kemudian, tanah ini termasuk lempung dengan perkiraan kinerja timbunan buruk sampai sedang, karena dari hasil pengujian tanah ini mempunyai berat volume kering maksimum ( $y d$ maks) 1.41 $1.81 \mathrm{gr} / \mathrm{cm}^{3}$ dan kadar air optimum (w opt) 15 $30 \%$. Dari analisis ini diperoleh, bahwa Model dan SNI 1742:2008 memiliki penilaian yang terhdap kinerja timbunan, sehingga aplikasi Model memenuhi syarat sebagai alat uji kepadatan ringan untuk tanah di laboratorium yang memiliki standar yang sama dengan SNI 1742:2008.

Berdasarkan analisis di atas, bahwa kepadatan maksimum tanah berdasarkan Model 
memiliki tingkat keyakinan $\geq 95 \%$ terhadap SNI

1742:2008 dan memiliki penilaian yang sama terhadap kinerja timbunan, sehingga aplikasi Model memenuhi syarat sebagai alat uji kepadatan ringan untuk tanah di laboratorium yang memiliki standar yang sama dengan SNI 1742:2008.

\section{DAFTAR PUSTAKA}

Hardiyatmo, H.C, (2012), Mekanika Tanah 1, Edisi Keenam, Gajah Mada University Press, Yogyakarta

http://ivanfaisalrahman.hyperphp.com, Menghitung Margin Error, diakses 13 Desember 2015

http://learnmine.blogspot.co.id, 04/01/2017

http://www.ilmulabtekniksipil.id, 05/01/2017

http://www.ilmusipil.com, diakses 05/01/2017

Kretjie dan Morgan (www. slideshare.net), diakses 6 Agustus 2014.

Muda, A (2016), Analisis Model Sebagai Alat Uji Kepadatan Ringan Untuk Tanah di Laboratorium,

Muda, A (2016), Jurnal Infoteknik Volume 17 No.1, Juni 2016, Model Pendekatan Alat Uji Kepadatan Ringan Untuk Tanah di Laboratorium, Fakultas Teknik Universitas Lambung Mangkurat, Banjarmasin
SNI 03-1966-1990, Metode Pengujian Batas Plastis Tanah

SNI 1965:2008, Cara Uji Penentuan Kadar Air Untuk Tanah dan Batuan di Laboratorium

SNI 3423:2008, Cara Uji Analisis Ukuran Butir Tanah 